\title{
Erratum to: Scintigraphic outlook of patients and regions with myocardial necrosis at myocardial perfusion scintigraphy
}

Olga James, MD, and Salvador Borges-Neto, MD, FACNM, FASNC, FACC, FAHA $^{\mathrm{a}}$

a Department of Radiology, School of Medicine, Duke University, Durham

\section{ERRATUM TO: J NUCL CARDIOL \\ DOI 10.1007/S12350-017-0796-0}

In the original article, the inclusion of the co-author (Salvador Borges-Neto) was neglected. In addition, the authors' affiliation was incomplete. The complete author list and the complete affiliation is shown in this erratum. The original article was corrected.

The online version of the original article can be found under doi: 10.1007/s12350-017-0796-0.

Reprint requests: Olga James, MD, Department of Radiology, School of Medicine, Duke University, Durham; olga.g.james@dm.duke.edu J Nucl Cardiol 2018;25:508.

$1071-3581 / \$ 34.00$

Copyright $@ 2017$ American Society of Nuclear Cardiology.

doi:10.1007/s12350-017-0861-8 